Article

\title{
Pharmacotechnical Development of a Nasal Drug Delivery Composite Nanosystem Intended for Alzheimer's Disease Treatment
}

\author{
Thomas Adnet ${ }^{1,2}$, Anne-Claire Groo $\left.{ }^{1, *} \mathbb{(}\right)$, Céline Picard ${ }^{3}$, Audrey Davis ${ }^{1} \mathbb{D}$, Sophie Corvaisier ${ }^{1}$, \\ Marc Since ${ }^{1}{ }^{(0)}$, Frédéric Bounoure ${ }^{4}$, Christophe Rochais ${ }^{1}{ }^{\circledR}$, Loïc Le Pluart ${ }^{5}$, \\ Patrick Dallemagne ${ }^{1}$ (I) and Aurélie Malzert-Fréon ${ }^{1, *}$ \\ 1 Normandie Univ, UNICAEN, CERMN, 14000 Caen, France; adnet.thomas.ph@gmail.com (T.A.); \\ audrey.davis@unicaen.fr (A.D.); sophie.corvaisier@unicaen.fr (S.C.); marc.since@unicaen.fr (M.S.); \\ christophe.rochais@unicaen.fr (C.R.); patrick.dallemagne@unicaen.fr (P.D.) \\ 2 CHU, 14000 Caen, France \\ 3 UNILEHAVRE, FR 3038 CNRS, URCOM, EA 3221, Normandie University,76063 Le Havre, France; \\ celine.picard@univ-lehavre.fr \\ 4 UFR of Health, Laboratory of Pharmaceutical \& Biopharmaceutical technology, UNIROUEN, Normandy \\ University, 76183 Rouen CEDEX, France; frederic.bounoure@univ-rouen.fr \\ 5 LCMT, UMR CNRS 6507, EnsiCaen UniCaen, 14000 Caen, France; loic.lepluart@ensicaen.fr \\ * Correspondence: anne-claire.groo@unicaen.fr (A.-C.G.); aurelie.malzert-freon@unicaen.fr (A.M.-F.); \\ Tel.: +33-231-566819 (A.M.-F.)
}

Received: 10 February 2020; Accepted: 9 March 2020; Published: 11 March 2020

\begin{abstract}
Direct nose-to-brain delivery has been raised as a non-invasive powerful strategy to deliver drugs to the brain bypassing the blood-brain barrier (BBB). This study aimed at preparing and characterizing an innovative composite formulation, associating the liposome and hydrogel approaches, suitable for intranasal administration. Thermosensitive gel formulations were obtained based on a mixture of two hydrophilic polymers (Poloxamer 407, P407 and Poloxamer 188, P188) for a controlled delivery through nasal route via liposomes of an active pharmaceutical ingredient (API) of potential interest for Alzheimer's disease. The osmolarity and the gelation temperature ( $\mathrm{T}^{\circ}$ sol-gel) of formulations, defined in a ternary diagram, were investigated by rheometry and visual determination. Regarding the issue of assays, a mixture composed of P407/P188 (15/1\%, w/w) was selected for intranasal administration in terms of $\mathrm{T}^{\circ}$ sol-gel and for the compatibility with the olfactory mucosal ( $280 \pm 20$ mOsmol, $\mathrm{pH}$ 6). Liposomes of API were prepared by the thin film hydration method. Mucoadhesion studies were performed by using mucin disc, and they showed the good natural mucoadhesive characteristics of in situ gel formulations, which increased when liposomes were added. The study demonstrated successful pharmacotechnical development of a promising API-loaded liposomes in a thermosensitive hydrogel intended for nasal Alzheimer's disease treatment.
\end{abstract}

Keywords: nose-to-brain delivery; nanocomposite; thermosensitive hydrogel

\section{Introduction}

Alzheimer's disease (AD) is the most frequent cause of dementia among the elderly [1]. This disease, characterized by an insidious decline in cognitive and non-cognitive functions, is devastating for patients, their family and society. Many types of neurotransmitters are affected in this chronic and progressive neurodegenerative disorder, and the relative importance of each in relation to clinical findings has not been fully elucidated. Today, no curative treatment exists. While current clinical therapy 
for $\mathrm{AD}$ patients is mainly symptomatic treatment enhancing cholinergic function using inhibitors of acetylcholinesterase (AChE) [2], the development of new drugs for a disease modifying approach is essential. Butyrylcholinesterase $(\mathrm{BuChE})$ is a serine hydrolase related to acetylcholinesterase that catalyzes the hydrolysis of choline and non-choline esters, including acetylcholine [3]. Consideration of the neurobiology of BuChE is particularly relevant nowadays in the treatment of neurodegenerative disorders, such as AD. Selective inhibitors of BuChE have been proposed for their potential to treat Alzheimer's disease [4].

$\mathrm{AD}$ and other types of neurodegenerative diseases are difficult to treat in particular because of the blood-brain barrier (BBB). As BBB restricts transport of drugs to the brain, very few drugs are actually available for treatment of $\mathrm{AD}$ [5]. While preventing the neurotoxic xenobiotics' access into the central nervous system (CNS) to protect it, it also strongly limits the administration of neuroprotective drugs to the CNS. The direct nose-to-brain delivery has appeared as a non-invasive powerful strategy to deliver drugs to the brain bypassing the BBB [6]. The most important direct pathway to the brain is the transport or the diffusion directly to the brain through the olfactory mucosa pathway in the olfactory region [7].

The intranasal delivery enhances targeting and reduced systemic side effects [8]. The direct nose-to-brain transport can reduce drug distribution to non-targeted sites, minimizing adverse effects. Scientists started to look for different approaches for brain delivery of drugs, and nasal administration has recently gained special interest. There are various approaches to facilitate nose-to-brain drug delivery, and among them, one finds the use of gelling formulation that inhibits the mucociliary clearance, and that of drug delivery nanosystems [9]. We chose to combine both strategies by the development of a nasal drug delivery composite nanosystem to deliver our active pharmaceutical ingredient (API) in the brain. This formulation is a thermogelling system, composed of liposomes. Firstly, these carriers may provide favorable characteristics to the drug such as enhanced absorption, mucoadhesion and increased stability. Secondly, using gels increases drug residence time in the nasal cavity for a better absorption.

Various API loaded in nanoparticles and intranasally administered were studied for the treatment of $\mathrm{AD}[10,11]$. For example, the intranasal administration of a donepezil-loaded liposome significantly increased drug delivery to the brain compared with the conventionally used products [12]. Similarly, the intranasal administration of rivastigmine-loaded liposomes enhanced brain concentrations of rivastigmine compared to the free drug [13]. These results were in accordance with other studies based on rivastigmine liposomal formulations [14,15], indicating the suitability of this approach in the treatment of AD.

As our API presents a high aqueous solubility $(>10 \mathrm{mg} / \mathrm{mL})$ and a limited permeability, it could be considered as a class III drug according to the drug biopharmaceutics classification system (BCS) [16]. Hydrophilic API are not suitable for absorption through nasal mucosa. As a consequence, loading the drug into flexible liposome overcomes this obstacle and facilitates the drug transfer across mucosa [17].

Liposomes can encapsulate hydrophilic and hydrophobic drugs. Hydrophobic drugs have affinity to the phospholipid bilayer, while hydrophilic drugs are entrapped in the aqueous cavity [18]. Liposomes are biocompatible, completely biodegradable, safe and non-immunogenic [19]. Thus, encapsulation into their aqueous core appears as a promising strategy for the brain delivery of hydrophilic API by intranasal route.

To optimize API remanence, we have chosen to develop an in situ forming gel: a polymer solution which gelifies in response to an external stimulus [20], here, the temperature. Being thermoresponsive, the system is intended to behave as a solution at room temperature in order to facilitate administration, and to become a gel in the nasal cavity at $34^{\circ} \mathrm{C}$.

Poloxamer is a water-soluble and, non-ionic triblock copolymer. It is constituted of a hydrophobic polyoxypropylene (POP) central block and two hydrophilic blocks of polyoxyethylene (POE). There are many types of Poloxamers, which differ in their molecular weight and the ratio of the POP and POE units present. Among the most frequently encountered Poloxamers are Poloxamers 188 
(P188, $\left.\mathrm{POE}_{75}-\mathrm{POP}_{30}-\mathrm{POE}_{75}\right)$ and 407 (P407, $\left.\mathrm{POE}_{101}-\mathrm{POP}_{56}-\mathrm{POE}_{101}\right)$. Due to their reversible thermal characteristics, Poloxamer-based hydrogels are interesting candidates as drug carriers. Consequently, these thermoreversible and not irritating gel have been largely investigated to develop mucoadhesive formulations [21]. P188 is interesting to use in association with P407 in order to modulate the Tsol-gel and the properties of gel. Indeed, Soliman et al. showed that P188 increased the Tsol-gel and mucoadhesive force of in situ thermo-sensitive gels for the vaginal administration of sildenafil [22]. Recently, Poloxamer 407 was used alone or with mucoadhesive polymer to prepare in situ hydrogels for therapy of neurodegenerative disease including Alzheimer's disease [23,24].

The in situ gel system containing liposomes enables mucoadhesion, improvement of drug permeability, and a sustained and controlled delivery $[25,26]$.

To optimize the persistence of the gel in the intranasal cavity, it may be advantageous to use mucoadhesive formulations by incorporating other polymers into the gel formulation. Thus, the addition of well know mucoadhesive polymers such as chitosan or hydroxypropyl methyl cellulose (HPMC) would improve mucoadhesive properties of the developed formulation.

Intranasal administration has been privileged because it is a non-invasive, painless method and usable for ambulatory treatment [27].

Hence, the aim of this study is to develop and characterize an innovative composite formulation, associating the liposome and hydrogel approaches, suitable for intranasal administration. To avoid adversely affecting the functions of the nasal mucosa and its cilia, we aimed that this formulation corresponds to European pharmacopeia criteria about nasal preparations, i.e., to be an isotonic formulation (280 $\pm 20 \mathrm{mOsmol})$, with a stabilized $\mathrm{pH}$ value $(6 \pm 3)$ [28].

\section{Materials and Methods}

\subsection{Materials $(A D)$}

Soybean, and egg phosphatidylcholine (SPC and EPC, respectively) were gifts from Lipoid GmbH (Ludwigshafen, Germany). Cholesterol (CHOL), Sepharose ${ }^{\circledR}$ CL-4B, and Chitosan oligosacharide lactate, donepezil, hydroxypropylmethyl cellulose, gellan gum, acetylthiocholine-iodide (ATC), butyrylthiocholine iodide and 5,5-dithiobis-(2-nitrobenzoic) acid (DTNB), human aceylcholinesterase (AChE), equine butyrylcholinesterase $(\mathrm{BuChE})$, donepezil were purchased from Sigma-Aldrich (Ludwigshafen, Germany). Tacrine was provided from Tocris (Lille, France). KolliphorßP407 $\left(\mathrm{POE}_{101}-\mathrm{POP}_{56}-\mathrm{POE}_{101}\right.$ triblock copolymer) and KolliphorßP188 ( $\mathrm{POE}_{75}-\mathrm{POP}_{30}-\mathrm{POE}_{75}$ triblock copolymer) were gifts from BASF (Levallois-Perret, France). Sodium chloride was purchased from Carlo Erba (Val de Reuil, France). Prisma Buffer HT pH 7,4, sink brain buffer, corticosterone and theophylline was obtained from pION (Billerica, MA, Etats-Unis, USA). Methanol, acetonitrile, water of HPLC grade, formic acid, sodium hydroxide, and hydrochloric acid were provided by Prolabo VWR International (Fontenay-sous-Bois, France).

\subsection{Characterization of the Active Pharmaceutical Ingredient}

\subsubsection{In Vitro Measurement of $\mathrm{AChE}$ and BuChE Activity}

The API inhibitory capacity on acetylcholinesterase (AChE) and Butyrylcholinesterase (BuChE) biological activity was evaluated through the use of the spectrometric method of Ellman [29], and realized according to the protocol already reported by our team [30]. Donepezil or tacrine were used as a reference standard. Assays were performed with a blank containing all components except acetyl- or butyrylthiocholine, to account for non-enzymatic reactions. The percent inhibition due to the presence of the test compound was calculated by the following expression: $\left(\left(v_{0}-v_{i}\right) / v_{0}\right) \times 100$, where $v_{i}$ is the rate calculated in the presence of inhibitor and $v_{0}$ is the enzyme activity. 
$\mathrm{IC}_{50}$ values were determined graphically by plotting the \% inhibition versus the logarithm of six inhibitor concentrations in the assay solution, using the GraphPad Prism software (version 6.01, GraphPad Software, La Jolla, CA, USA). All experiments were performed in $n=3$.

\subsubsection{Parallel Artificial Membrane Permeability Assay (PAMPA)}

The PAMPA-GIT experiments were conducted using the Pampa Explorer Kit (Pion Inc., Billerica, MA, USA) according to manufacturer's protocol, and realized according to the protocol already reported by our team [31]. Quality control standards with known Pe were used as references: the low $/$ moderately permeable corticosterone $(\mathrm{Pe}=202.0 \mathrm{~nm} / \mathrm{s}$ at $\mathrm{pH}=7.4)$ and theophylline $(\mathrm{Pe}=5.0 \mathrm{~nm} / \mathrm{s}$ at $\mathrm{pH}=7.4$ ).

\subsection{Preparation of Liposomes}

\subsubsection{Formulation of Liposomes}

Liposomes were formulated according to the adapted method of the thin lipid film hydration [32]. A lipid blend of soybean phosphatidylcholine (SPC) and cholesterol (CHOL) was used at a molar ratio 8:1. Lipid solutions in chloroform/methanol (4:1) were evaporated under nitrogen flow, and left under vacuum for 3-4 $\mathrm{h}$ to form a lipid film. This thin lipid film was then hydrated in water or API solution, and vortexed. The yielded multilamellar vesicles (MLVs) were then extruded 13 times with a mini-extruder (Avanti Polar Lipids, Inc., Alabaster, AL, USA) through polycarbonate membranes with a pore diameter of $100 \mathrm{~nm}$ (Avanti Polar Lipids, Inc., Alabaster, AL, USA) to form large unilamellar vesicle (LUVs).

\subsubsection{Characterization of Liposomes by Dynamic Light Scattering}

The average hydrodynamic diameter associated with the polydispersity index (PDI) of the formulated LUVs and the formulated LUVs dispersed in polymer solution were measured by dynamic light scattering (DLS) using a NanoZS ${ }^{\circledR}$ apparatus (Malvern Instruments SA, Worcestershire, UK). The zeta potential was calculated from the electrophoretic mobility using the Smoluchowski equation, also using a NanoZS ${ }^{\circledR}$ apparatus. The measurements were performed in triplicate at $25^{\circ} \mathrm{C}$, after a 1:100 dilution in water.

\subsubsection{Entrapment Efficiency}

Entrapment of the active pharmaceutical ingredient (API) into the liposome was determined. Liposomes were separated by Sepharose ${ }^{\circledR}$ CL-4B column. The API content in the liposome fraction was analyzed by HPLC and the encapsulation efficiency (\% EE) was calculated by considering the initial amount of drug added in the formulation using Equation (1):

$$
\% \mathrm{EE}=\frac{\text { The amount present in liposomes fraction }}{\text { Total amount of API added }} \times 100
$$

Drug loading (DL) was calculated using Equation (2):

$$
\% \mathrm{DL}=\frac{\text { Weight of API entrapped within liposomes }}{\text { Total weight of oil phase of the liposomes }} \times 100
$$

Total weight of oil phase of the liposome corresponds to the total amount of excipients (excluding the water phase) and API used for the preparation of the liposomes.

\subsubsection{UHPLC}

API concentrations were measured by high-performance liquid chromatography (UHPLC). The apparatus was composed by an Agilent binary pump 1290, an autosampler 1290 and a diode array 
UV detector 1260 (Agilent technologies, Santa Clara, CA, USA). The column used was a reversed phase column C18 (Restek ${ }^{\circledR}$ Ultra, $5 \mu \mathrm{m}, 2.1 \times 50 \mathrm{~mm}$, Lisses, France). The injection volume and the run-to-run time were $4 \mu \mathrm{L}$ and $1.53 \mathrm{~min}$, respectively. The flow rate was $0.8 \mathrm{~mL} / \mathrm{min}$ and the detection wavelength was $214 \mathrm{~nm}$. The mobile phase was initially composed of a mixture of $3 \%$ water containing $0.1 \%(v / v)$ formic acid (A) and $97 \%$ acetonitrile containing $0.1 \%(v / v)$ formic acid (B). Then, the composition reached $90 \%$ of B after $0.8 \mathrm{~min}$, then $60 \%$ of B after $1.5 \mathrm{~min}$ by applying a linear gradient, maintained for $1 \mathrm{~min} .5 \%$ of $\mathrm{B}$ was then reached at $2.51 \mathrm{~min}$, maintained for $1.5 \mathrm{~min}$ and returned to the initial conditions. Linearity was observed in the range from 2.5 to $100 \mu \mathrm{M}$ with a determination coefficient greater than 0.999 . The column was maintained at $25^{\circ} \mathrm{C}$. It was checked that in presence of liposome and gel, no interaction with API is present.

\subsection{Preparation of the In Situ-Forming Gel}

\subsubsection{Gel Formulation}

The gel was made on a weight basis using the "cold method" [33]. Poloxamer P407 was mixed with Poloxamer P188, the API, chitosan, gellan gum, HPMC or liposomes and demineralized water ( $\mathrm{pH}$ 6-7) under magnetic stirring at $500 \mathrm{rpm}$ during at least $30 \mathrm{~min}$ at $4{ }^{\circ} \mathrm{C}$, until a homogenous solution was obtained. After dissolution, solutions were stored at $4{ }^{\circ} \mathrm{C}$ for $2 \mathrm{~h}$ before characterization. Concentrations of Poloxamer P407 (14-25\%, w/v) and Poloxamer P188 (0-10\%, w/v) were optimized to obtain an instantly gelling system at physiological conditions. API concentration of $1 \mathrm{mg} / \mathrm{mL}$ was used.

\subsubsection{Gel Characterization}

Physicochemical Properties

The $\mathrm{pH}$ of formulation was measured using a pH-meter (Eutech instrument, Landsmeer, The Netherlands). To determine osmolarity, a micro-osmometer autocal type 13 based on the freezing-point method (Roebling, Berlin, Germany) was used. $100 \mu \mathrm{L}$ of each formulation were introduced in a microtube and measurements were performed. Gelation temperature $\left(\mathrm{T}_{\text {gel }}\right)$ of formulations was investigated by visual determination. Briefly, formulation was placed in transparent vials under magnetic stirring $\mathrm{s}$ in a water bath heated from temperature of $15{ }^{\circ} \mathrm{C}$ to $50{ }^{\circ} \mathrm{C}$ (at the rate of $2^{\circ} \mathrm{C} / \mathrm{min}$ ). The gelation temperature was recorded when the magnetic bar stopped moving because an increase in viscosity. The visual determinsation of gelation temperature was confirmed by rheometry method.

\section{Rheological Evaluation}

All the rheological characterizations were carried out on a rheometer AR1000 (TA Instruments, Guyancourt, France) equipped with a cone-plate geometry $\left(4 \mathrm{~cm}, 1.59^{\circ}\right)$.

Gelation temperature determinations were performed in oscillatory mode. The storage and loss moduli were measured as a function of temperature (from 15 to $50{ }^{\circ} \mathrm{C}$ at $5{ }^{\circ} \mathrm{C} / \mathrm{min}$ ) with an oscillatory stress value maintained at $25 \mathrm{~Pa}$ in order to ensure being in the linear viscoelastic region in both the liquid and solid state. The frequency was set at $1.0 \mathrm{~Hz}$ during the measurements.

The viscosity of the gel forming solutions was measured as a function of shear rate (from $0.1-100 \mathrm{~s}^{-1}$ then from $100-0.1 \mathrm{~s}^{-1}$ ) in steady state at $34{ }^{\circ} \mathrm{C}$ to evaluate the interactions between the formulation components.

In order to evaluate the gel strength, storage modulus evolution of hydrogels was recorded during stress sweeps performed above $\mathrm{T}_{\text {gel }}$ at $50^{\circ} \mathrm{C}$ from 0 to $600 \mathrm{~Pa}$ in oscillatory mode.

\subsection{In Vitro Evaluation of Mucoadhesion}

The mucoadhesive strength of empty gels (blank) and those containing liposomes was determined using a Texture Analyzer TA-XT Plus (Stable Micro Systems, Cardiff, UK) and a mucin disc test. Porcine 
mucin discs (250 mg, $13 \mathrm{~mm}$ diameter), prepared by direct compression (10 $\mathrm{t}$ for $30 \mathrm{~s}$ of pig gastric mucin), were horizontally attached onto the lower face of an inert horizontal polycarbonate probe. A force of $5 \mathrm{~g}$ was applied for $120 \mathrm{~s}$ to ensure contact between formulations and the mucin disc. Then, the probe was raised at a speed of $0.5 \mathrm{~mm} / \mathrm{s}$. The mucoadhesive strength was determined from the force of detachment. Measurements were run at $37^{\circ} \mathrm{C}$. A cylindrical probe $\mathrm{P} / 35$ (13 mm diameter, aluminum) was used, and an amount of $5 \mathrm{~mL}$ of product was delivered on the base.

\subsection{In Vitro Release Profile}

Kinetic release studies were performed in nasal simulated fluid at $34{ }^{\circ} \mathrm{C}$ using Franz cells. $200 \mu \mathrm{L}$ of formulations was placed into a cellulose ester dialysis tube with $100 \mathrm{kDa}$ pore size (Spectrum lab, Gardena, CA, USA), and incubated in simulated nasal fluid (SNF) pH 6.5. at $34{ }^{\circ} \mathrm{C}$ under magnetic stirring. SNF was an aqueous solution containing $8,77 \mathrm{mg} / \mathrm{mL}$ of $\mathrm{NaCl}, 2.98 \mathrm{mg} / \mathrm{mL} \mathrm{KCl}$ and $0.59 \mathrm{mg} / \mathrm{mL}$ $\mathrm{CaCl}_{2}$. The receptor solution was withdrawn (samples of $100 \mu \mathrm{L}$ ), was replaced at various time points by fresh SNF and the amount of API released from the formulations was determined by HPLC after a 10-fold dilution in methanol. All measurements were performed in triplicate.

\subsection{Statistical Analysis}

Results were expressed as mean values \pm standard error of the mean (SEM) or as mean values \pm standard deviation. A Student's t-test was used for statistical comparison/analysis, and $P<0.05$ was considered statistically significant.

\section{Results and Discussion}

\subsection{Characterization of the Active Pharmaceutical Ingredient (API)}

API inhibitor capacity of human AChE and equine BuChE was assessed using the Ellman assay [29]. In this test, Donepezil and Tacrine were used as reference AChE and BuChE inhibitors, respectively. The results are depicted in Table 1.

Table 1. Human Acetylcholinesterase ((h) AChE) and equine Butyrylcholinesterase ((eq) BuChE) inhibitory activities (IC50) by Ellman method.

\begin{tabular}{ccc}
\hline & (h) AChE IC50 (nM & (eq) BuChE IC50 (nM) \\
\hline Donepezil & $11 \pm 3$ & - \\
Tacrine & - & $2 \pm 1$ \\
API & $14,520 \pm 1,485$ & $573 \pm 40$ \\
\hline
\end{tabular}

Note: values are expressed as mean \pm standard error of the mean (SEM) of at least two experiments.

API appeared able to inhibit $\mathrm{BuChE}$ with $\mathrm{IC}_{50}$ value of $573 \pm 40 \mathrm{nM}$, whereas its displays a negligible $\mathrm{AChE}$ inhibitor activity with $\mathrm{IC}_{50}$ value of $14,520 \pm 40 \mathrm{nM}$. Thus, API shows a specific submicromolar inhibition of BuChE.

Both cholinesterase enzymes $\mathrm{AChE}$ and BuChE are involved in the hydrolysis of acetylcholine (ACh). In the healthy brain, AChE predominates on BuChE, that is considered to play a minor role in regulating brain levels of $\mathrm{ACh}$. However, during progression of $\mathrm{AD}$ in certain brain regions including cortical areas, AChE activity declines while BuChE activity remains unaffected or progressively increases [34]. Finally, in advanced stages of AD, BuChE is considered to play a prominent role in regulating brain $\mathrm{ACh}$ levels [35]. Thus, BuChE appears as a valuable target to improve the cholinergic deficit, due to its increasing role predicted in regulating brain ACh levels as the disease progresses. Furukawa-Hibi et al. demonstrated that BuChE inhibition, as well as AChE inhibition, is a viable therapeutic strategy for cognitive dysfunction in AD. Indeed, a selective BuChE inhibitor provides beneficial effects on the cognitive dysfunction induced by amyloid- $\beta$ peptide in mice [36]. From our 
experimental results, our API shows a specific submicromolar inhibition of BuChE without affecting AChE (i.e., 25-fold BuChE selectivity). This activity is very promising, especially if compared with reported equine BuChE inhibitory activity of other compounds, e.g., a new series of pyrazinamides, whose showed $\mathrm{IC}_{50}$ micromolar values [37].

The cholinesterase inhibitory activity of new compounds is classically evaluated using equine serum BuChE due to the economic viability of this enzyme. Purified human BuChE has limited availability from commercial sources, making equine $\mathrm{BuChE}$ a reasonable alternative [38]. In the study of Wu et al., synthetic compounds showed similar effectiveness in inhibiting BuChE from equine and human plasma, but with a higher potency over the human enzyme [39]. Similarly, Dighe et al. have shown that their lead was 2-fold more potent in inhibiting human BuChE than equine BuChE [40]. In the same way, we could hope for a better activity in human BuChE.

Having a selective inhibitor of BuChE is innovative because there is currently no equivalent drug available on the market. The API could have a positive role in the attention, executive function, emotional memory and behavior of patients at advanced stages AD by inhibiting the BuChE present in CNS neurons.

To determine the capacity to reach the CNS, the permeability must be evaluated. To analyze the passive permeability characteristics of API, we measured BBB permeability by a PAMPA model, well adapted to High Throughput Screening (HTS) [41]. Theophylline $(\mathrm{Pe}=5.0 \pm 0.0 \mathrm{~nm} / \mathrm{s})$, and corticosterone $(\mathrm{Pe}=202.0 \pm 3.0 \mathrm{~nm} / \mathrm{s})$ were used as low and high permeability standards, respectively. The API poorly diffused through the lipid bilayer, since Pe values $(\leq 20.4 \pm 3.0 \mathrm{~nm} / \mathrm{s})$, significantly lower than the positive control, indicated a potential difficulty in crossing the BBB. Thus, because of this limited permeability and its good water solubility $(>10 \mathrm{mg} / \mathrm{mL})$, the API can be considered as a class III BCS drug [16]. This poor BBB permeability, probably related to the hydrophilic character of the API, would lead to a poor brain bioavailability after intravenous administration.

However, whereas intravenous administration of API is unlikely to reach CNS, BuChE inhibition must occur in the CNS to be a viable therapeutic strategy in advanced AD [3]. Moreover, the API peripheral biodistribution could lead to important side effects, if it is not controlled and limited. Indeed, the heart is naturally rich in cholinesterase (ChE). Its inhibition may affect the cardiac function, especially in elderly patients, many of them having concomitant cardiovascular diseases. Peripheral $\mathrm{ChE}$ inhibition potentiates the cardio-inhibitory effect with retarding ACh degradation and leads to negative chronotropic and dromotropic effects through muscarinic receptors [42]. As a consequence, a CNS selectivity is highly desired to avoid any dramatic side effect and improve API efficiency.

Nose-to brain delivery is a powerful strategy to increase this expected CNS selectivity.

Drug nasal delivery enables to bypass BBB and permits the API brain delivery. Nevertheless, this route of administration may be limited by enzyme degradation and quick mucociliary clearance [43] if formulation is not optimized. To increase drug transport efficiency into CNS via intranasal delivery, we have chosen to develop an innovative composite formulation based on liposomes included in gels.

\subsection{Preparation of Liposomes}

Unloaded (i.e., blank) and API-loaded liposomes (API-Lip) were formulated by the thin lipid film hydration method. Unloaded and API-lip were characterized in terms of granulometric properties, zeta-potential, and encapsulation efficiency (Table 2). Various SPC and cholesterol concentrations, and molar ratios were assayed, without any significant influence on the liposomes physico-chemical properties (results not shown).

For the retained liposomal formulation, based on a $120 \mathrm{mM}$ SPC and cholesterol mixture, used in a molar ratio of 8:1, the mean hydrodynamic diameter was $119.0 \pm 0.7 \mathrm{~nm}$ for blank Lip, and $114.9 \pm 2.4 \mathrm{~nm}$ for API-Lip. For all the formulations, the polydispersity index (PDI) values were lower than 0.1, indicating monomodal size distributions. Encapsulation efficiency of API in Lip was $11 \%$. This corresponds to an API concentration of $1.2 \pm 0.1 \mathrm{mg} / \mathrm{mL}$, and a drug loading of 
$1.4 \pm 0.1 \%$. SPC/cholesterol liposome formulations are widely found in the literature, and the particle size properties obtained are comparable to ours results [44,45].

Table 2. Properties of the developed liposomes.

\begin{tabular}{|c|c|c|c|c|c|c|}
\hline & $\begin{array}{l}\text { Hydrodynamic } \\
\text { Diameter }(\mathrm{nm})\end{array}$ & PDI & $\mathrm{ZP}(\mathrm{mV})$ & $\%$ EE & $\% \mathrm{DL}$ & $\begin{array}{c}\text { Concentration } \\
(\mathrm{mg} / \mathrm{mL})\end{array}$ \\
\hline Blank liposomes & $119.0 \pm 0.7$ & $0.032 \pm 0.004$ & $-5.5 \pm 0.3$ & - & - & - \\
\hline API-Lip & $114.9 \pm 2.4$ & $0.048 \pm 0.020$ & $-11.2 \pm 1.4$ & $11.1 \pm 1.0$ & $1.4 \pm 0.1$ & $1.2 \pm 0.1$ \\
\hline Blank liposomes in gel & $140.8 \pm 0.5$ & $0.078 \pm 0.004$ & $-6.6 \pm 0.5$ & - & - & - \\
\hline
\end{tabular}

The nose-to-brain passage of nanoemulsions has been studied through live imaging or ex vivo histological examination in rats after nasal administration by Ahmad et al. [46]. This study demonstrated that nanoparticle size plays a determinant role, by directly influencing their in vivo fate. NEs with a size of about $100 \mathrm{~nm}$ have longer retention time in nostrils and slower mucociliary clearance than larger ones (i.e., $>200 \mathrm{~nm}$ ). NEs of $100 \mathrm{~nm}$ can be transported through the trigeminal and the olfactory nerves to the olfactory bulb. Subsequent uptake and translocation of nanoparticles along axons of the olfactory nerve have been shown in non-human primates and rodents [47]. Morrison and Costanzo established that the diameter of a human olfactory neuron axon ranges from 100 to $700 \mathrm{~nm}$ [48]. Therefore, theoretically, axonal transport of up to $\sim 500 \mathrm{~nm}$ diameter particles is possible in humans. Al Asmari et al. showed that liposomal formulation of donepezil with a size of $120 \mathrm{~nm}$, significantly increased brain concentration after intranasal administration [12]. Similarly, pharmacokinetic and brain targeting studies in rats revealed a significantly high concentration of drug in brain following intranasal administration of solid lipid nanoparticles of donepezil in comparison with a donepezil solution [49]. This demonstrates brain targeting efficiency of solid lipid nanoparticles of $120 \mathrm{~nm}$. As a consequence, liposomes of $120 \mathrm{~nm}$ appear really suitable for brain targeting through nasal route and could reach the olfactory bulb through axons.

Furthermore, in ours assays, zeta potential values were only very slightly negative, and broadly neutral for both blank Lip and API-Lip. Surface charge of the nanoparticles could influence the mechanisms involved in their transport from the nasal cavity to the CNS. Indeed, the olfactory pathway is mainly responsible for the translocation of negatively charged nanoparticles, whereas the positively charged nanoparticles reach the brain more slowly, by involving the trigeminal pathway [50]. Intranasally applied nanoparticles have to penetrate the mucus layer covering nasal mucosa to reach the olfactory mucosa, and thus the CNS [51]. Interactions between particles and mucus could lead to trapping and wrapping of nanoparticles in mucus, making them less suitable as efficient vehicles for nose-to-brain delivery [27]. Uncharged nanoparticles, which do not interact with mucus are able to diffuse through mucus more efficiently [52].

Thus, nanoparticles appear well designed to permeate mucus by being small enough, neutral in net surface charge and coated densely with charged groups that prevent hydrophobic bonding to mucins [53].

The liposomes, that we have formulated, present surface charges close to neutrality and very slightly negative, as well in the absence (potential $\zeta=-5.5 \pm 0.3 \mathrm{mV}$ ) as in the presence of the encapsulated API (potential $\zeta=-11.2 \pm 1.4 \mathrm{mV}$ ), and although in gels (potential $\zeta=-6.6 \pm 0.5 \mathrm{mV}$ ) (see after). In view of these particle size and surface charge properties of the formulated liposomes, the prerequisites for allowing the addressing and diffusion of the API towards the olfactory mucosa appear to be satisfied.

\subsection{Preparation of in Situ-Forming Gel}

We attempted to develop an aqueous formulation of API that allows an increased residence time in the nasal cavity. Hydrogels are a particularly attractive type for intranasal API administration. 
Widely used in various medical fields [54-56], the hydrogels are devoid of potentially toxic organic solvents since they are composed of a large amount of water and a network of cross-linked polymers.

Poloxamers are biodegradable by erosion [57] and biocompatible polymers [58]. Based on these safety data and the information that the manufacturing process can be controlled to limit unwanted impurities, the Cosmetic Ingredient Review Expert Panel concluded that poloxamers are safe as used [59].

Poloxamers are composed of a hydrophobic POP block, sandwiched between two hydrophilic POE blocks [60]. Among them, P407 is a non-ionic surfactant, endowed with gelation properties above a defined sol-gel transition temperature $\left(\mathrm{T}_{\text {gel }}\right)$. Below this temperature, the sample remains fluid, and above, the solution becomes semi-solid. This phenomenon of thermogelling is perfectly reversible. When the temperature increases, copolymer macromolecules aggregate into micelles. This micellization is due to the dehydration of hydrophobic POP blocks, which represents the very first step towards gelation. When the polymer concentration is high enough, the micellization is followed by gelation.

Surprisingly and unlike some empirical data from the literature [61], we experimentally observed that hydrogel formulations based on the sole P407 could not lead to a $\mathrm{T}_{\text {gel }}$ compatible with our specifications (data not shown). According to information provided by the supplier, the production mode of P407 has recently evolved, thus modifying the average molecular weight of the poloxamers produced, and resulting in a direct modification of the gelation temperatures. Hence, to further modulate sol-gel temperature of P407 hydrogel, P188 was added in defined proportions.

Various ternary mixtures of P407, P188, and water were tested. The gelation temperatures and osmolarity of theses formulations were plotted on ternary diagrams (Figure 1). For all the formulations, $\mathrm{pH}$ is acceptable (optimum $\mathrm{pH}$ for nasal rote is $6 \pm 3$ ). Increase of $\mathrm{P} 407$ relative content leads to a gelation temperature decrease, and to higher osmolarity values. P188 relative content increases both the gelation temperature and the osmolarity, as previously reported in the literature [62].

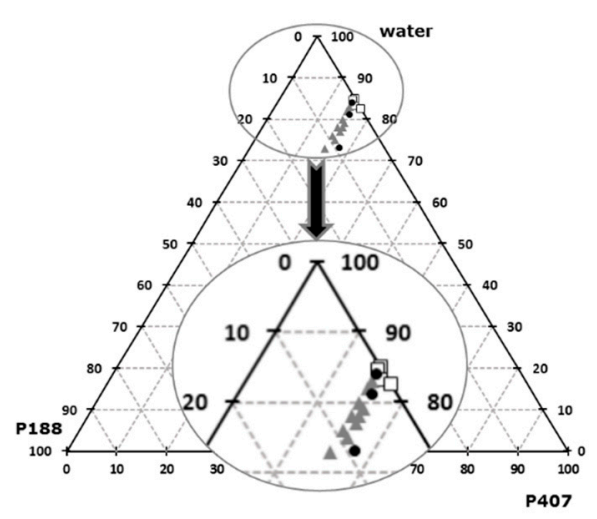

(a)

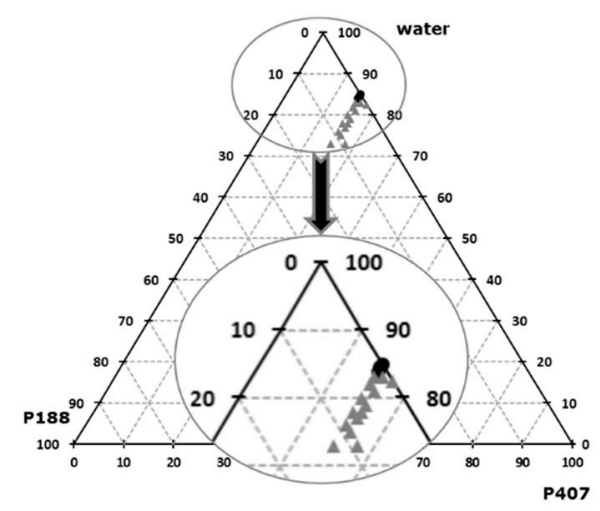

(b)

Figure 1. Ternary mix of Poloxamers 407/188 / H2O, sol-gel transition temperature (a), osmolarity (b).

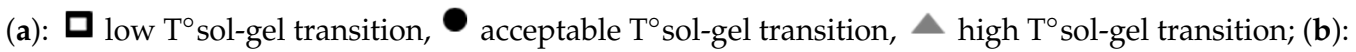
acceptable osmolarity, $\Delta$ High osmolarity.

By using $15 \mathrm{wt} \%$ of $\mathrm{P} 407$ and $1 \mathrm{wt} \%$ of $\mathrm{P} 188$, an optimal formulation is obtained, characterized by a gelation temperature of $34.5 \pm 0.3^{\circ} \mathrm{C}$, an osmolarity of $277 \pm 4 \mathrm{mOsm}$, and a pH of 6.5. Gelation temperature of this P407/P188 mixture was confirmed by rheological determination, illustrated by the sudden increase of the storage modulus as the gel forms (Figure 2). When the storage modulus value overcomes the loss modulus value, the elastic behavior prevails on the viscous behavior. The physicochemical properties of this formulation are therefore suitable for intranasal administration according to the European pharmacopeia specifications [28], since the use of this isotonic formulation, with a stabilized $\mathrm{pH}$ value, would not adversely affect the functions of the nasal mucosa and its cilia. 


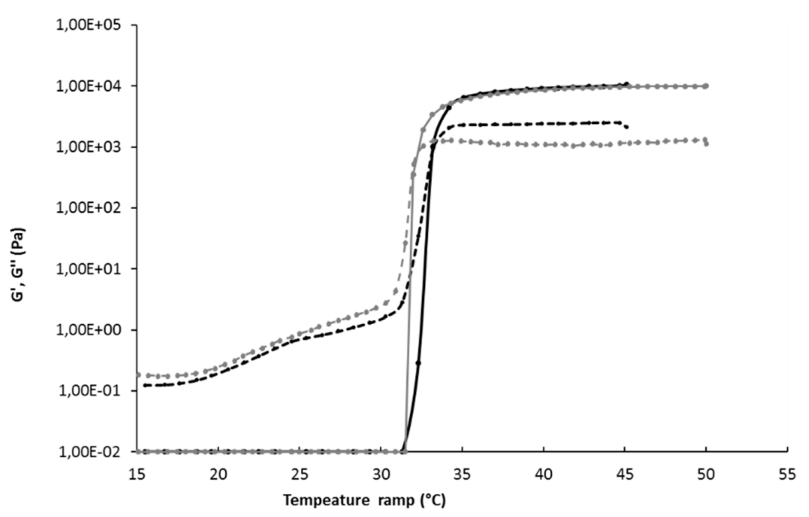

Figure 2. Rheology determination of gelation temperature of gel 15/1 with and without liposomes. Black continuous line G' storage modulus of Gel 15/1, black broken line G" loss modulus of gel 15/1, grey continuous line $\mathrm{G}^{\prime}$ storage modulus of Gel 15/1 with liposome, grey broken line $\mathrm{G}^{\prime \prime}$ loss modulus of gel15/1 with liposome.

\subsection{Preparation of API Delivery Composite Formulation}

In situ forming gel containing liposomes was prepared by the addition of poloxamers to an aqueous solution containing formulated liposomes. In these conditions, liposomes present higher mean hydrodynamic diameter values $\left(140.8 \pm 0.5 \mathrm{~nm}\right.$ in the poloxamer solution at $25^{\circ} \mathrm{C}$ vs. $119.0 \pm 0.7 \mathrm{~nm}$ just after liposome formulation). The PDI remained lower than 0.1 , and the zeta potential values remained broadly neutral (Table 2). This increase in the average liposome diameter included in the P407/P188 gel formulation may suggest an interaction between the poloxamers and the phospholipids forming the liposomes.

The addition of liposomes in gel formulation did not significantly modify the gelation temperature (Figure 2), nor the osmolarity (Table 3). The $\mathrm{pH}$ value decreased slightly but remained in the optimum value range. Free API also did not interfere with gel properties (Table 3). Thus, neither API nor liposome addition to P407/P188 (15/1 wt\%) gel significantly changed the gel formulation properties that respect the nasal physiologic conditions.

Table 3. Properties of gels.

\begin{tabular}{|c|c|c|c|c|c|}
\hline & Optimum & $\begin{array}{c}\text { P407/P188 } \\
\text { (15/1 wt \%) }\end{array}$ & $\begin{array}{c}+ \text { API } \\
1 \mathrm{mg} / \mathrm{mL}\end{array}$ & $\begin{array}{l}+ \text { Liposomes } \\
\quad 60 \mathrm{mM}\end{array}$ & $\begin{array}{l}\text { +Liposomes } \\
60 \mathrm{mM}+\text { API }\end{array}$ \\
\hline Tsol-gel $\left({ }^{\circ} \mathrm{C}\right)$ & $32-35$ & $34.5 \pm 0.3$ & $34.8 \pm 1.2$ & $30.9 \pm 1.0$ & $32.6 \pm 1.0$ \\
\hline Osmolarity (mOsm) & $280 \pm 20$ & $277 \pm 4$ & $287 \pm 6$ & $280 \pm 5$ & $293 \pm 5$ \\
\hline $\mathrm{pH}$ & $6 \pm 3$ & 6.5 & 6.5 & 5.5 & 5.5 \\
\hline
\end{tabular}

Note: values are expressed as mean \pm standard deviation $(n=3)$.

The rheological behavior of gel formulations containing liposomes or not were determined during shear rate ramps. In all cases, the shear viscosity progressively decreased (shear thinning) when the shear rate increased. All formulations behaved as a shear-thinning (non-Newtonian) fluids. The presence of liposomes increased the viscosity regardless of the shear rate, and higher content of liposomes led to higher viscosity (Figure 3). Such a viscosity increase with the dispersed phase concentration is classically observed for emulsions or suspensions.

To evaluate the strength of the gels above $T_{\text {gel }}$, the evolution of storage $\left(G^{\prime}\right)$ and loss $\left(G^{\prime \prime}\right)$ moduli of the gel and liposomes-containing gels were measured as a function of the oscillatory stress (Figure 4). For all gels, $G^{\prime}$ was much higher than $G^{\prime \prime}$ at low oscillatory stress, which is typical of solid-like materials. The presence of liposomes in the hydrogel significantly increased the storage modulus, and this increase was higher if liposome concentration increased. The stress at which the hydrogel lost $50 \%$ of its stiffness also increased significantly with the liposome concentration. Thus, it appears that liposomes simultaneously increase the hydrogel's stiffness and its strength. This leads us to 
think that liposomes interact with poloxamers, and play a role in the gel structuration. Moreover, the increase of liposomes average diameter in presence of poloxamers could also be related to interactions between poloxamers with the liposomes surface. Indeed, poloxamers exhibit surfactant properties and could interact with the phospholipid bilayer. Bochot et al. reported a destabilization of liposomes by P407 at low concentration [63]. P407 has a different behavior depending on its concentration in the formulation. Within dilute solutions ( $2 \%)$, its chains possess a greater fluidity that could lead to the insertion into phospholipid bilayer. A study of $\mathrm{Wu}$ and Lee also reports the existence of a saturation concentration of poloxamers, below which poloxamers can insert themselves in a lipid bilayer without disrupting liposomes and above which they instead disintegrate liposomes [64]. Polymer-liposomes complexes were prepared by $\mathrm{Cho}$ et al. The size of these complexes increased as the polymer content increased [65]. Polymer interactions with membranes would be due in particular to the central POP hydrophobic part of the copolymers [66]. There are two possibilities to explain the increase of liposome size: either the inclusion (association) of the polymers within the lipid bilayers or their adsorption on the vesicle surfaces. Based on adsorption method, Tian et al. prepared liposomes surfaces modified with P188 [67]. On the same way, the size of the liposomes gradually increased with increasing P188 content. Anyway, in our present study, whatever the precise interactions between poloxamers and liposomes, they do not affect sol-gel transition temperature but modify gel properties.

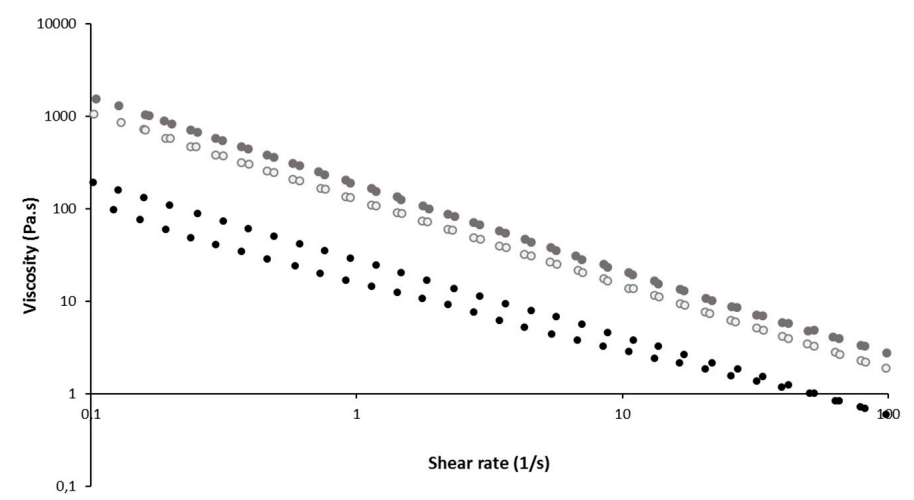

Figure 3. Shear stress-viscosity vs. deformation at $34{ }^{\circ} \mathrm{C}$ of gel $15 / 1$ with and without liposomes (Shear-viscosity results). Black cercle: Gel 15/1, grey empty cercle: Gel 15/1 with liposome $60 \mathrm{mM}$, grey full cercle: gel 15/1 with liposome $120 \mathrm{mM}$.

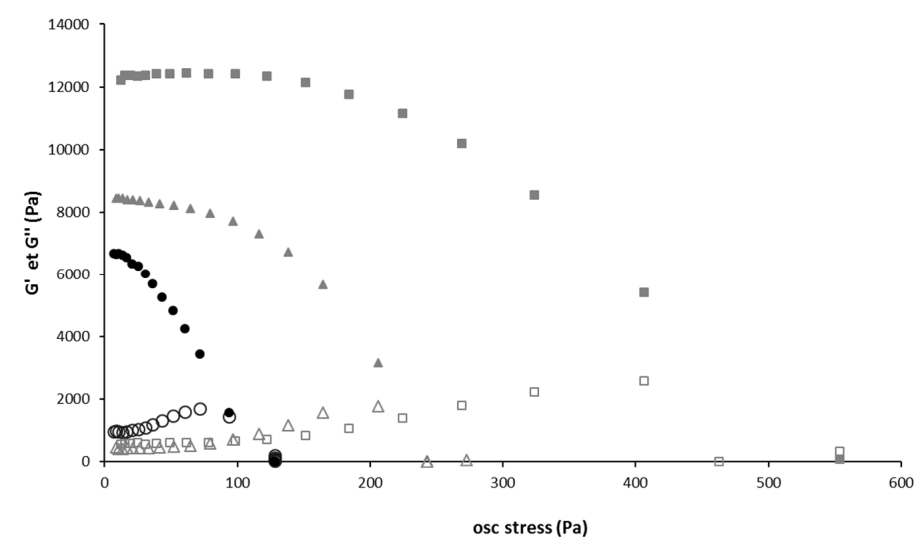

Figure 4. Strain sweep of gel with and without liposome.Storage $\left(G^{\prime}\right)$ and loss $\left(G^{\prime \prime}\right)$ moduli as a function of the oscillation stress. Black full circle: $G^{\prime}$ storage modulus of Gel 15/1, grey full triangle: $G^{\prime}$ storage modulus of Gel 15/1 with liposome $60 \mathrm{mM}$, grey full square: $\mathrm{G}^{\prime}$ storage modulus of Gel 15/1 with liposome $120 \mathrm{mM}$, Black empty circle: G" loss modulus of Gel 15/1, grey empty triangle: G" loss modulus of Gel 15/1 with liposome $60 \mathrm{mM}$, grey empty square: G" loss modulus of Gel 15/1 with liposome $120 \mathrm{mM}$. 


\subsection{Mucoadhesion Properties}

The thermosensitive properties of $\mathrm{P} 407$ have been widely exploited in the development of in situ nasal forming gels [68]. In contrast to P188, P407 is rather described as having limited mucoadhesion properties [26]. For this reason, it appeared interesting to integrate in the formulation a highly mucoadhesive polymer in order to optimize the interactions between the gel and the nasal mucosa. Chitosan and hydroxypropylmethyl cellulose (HPMC) are very widely described as mucoadhesive excipients, able to be incorporated in a gel in order to increase its mucoadhesion properties, and promote the API diffusion to the CNS [62].

In our studies, it appeared that the addition of excipients (HPMC or chitosan), at the defined classically used concentration of $0.5 \mathrm{wt} \%$, didn't significantly affect the sol-gel temperature (data not shown).

Mucoadhesion performance of these formulations were assessed on a mucin disc (Figure 5). In the literature, when the concentration of HPMC increased from $0.1 \%$ to $1.0 \%$ in P407/P188/HPMC gel, an increase in mucoadhesive strength was measured from $4560 \mathrm{dyn} / \mathrm{cm}^{2}$ to $10935 \mathrm{dyn} / \mathrm{cm}^{2}$ [23]. Surprisingly, in our case, no difference was observed between mucoadhesion properties of the gel formulated either without or with $0.5 \mathrm{wt} \%$ HPMC or chitosan. For chitosan, this unexpected result could be due to the low molecular weight of the polysaccharide, that we used. Indeed, after comparing different types of chitosans, some authors previously showed that the increase in the chitosan molecular weight and viscosity could expand the adhesiveness of gels [69].

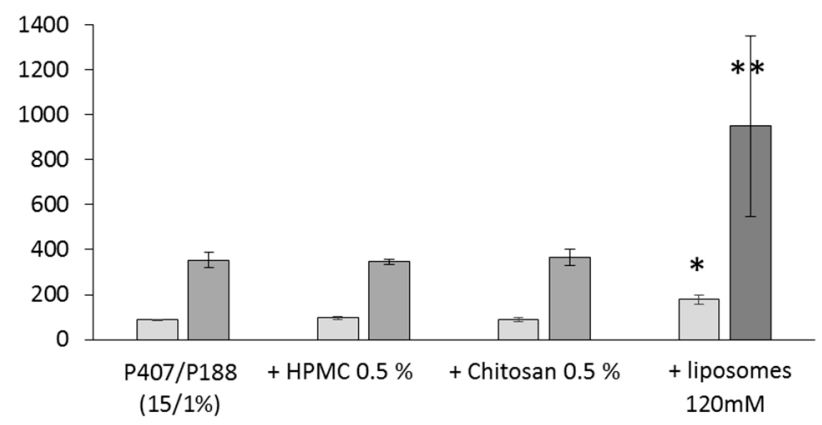

Figure 5. Mucoadhesion studies. Each point represents mean \pm standard deviation $(n=4)$; ${ }^{*}$ versus $15 / 1 \% p<0.01{ }^{* *}$ versus $15 / 1 \% p<0.001$. $\square$ detachment Force $(\mathrm{mN}), \square$ adhesion work (mN.mm).

On the contrary, liposome addition in the gel led to a significant increase of the detachment force and of the adhesion work (Figure 5). Poloxamers are able to form entanglements or non-covalent bonds with mucus, thus favoring a greater degree of interaction with various biological tissues [21]. In our formulation, interactions between liposomes and poloxamers could impact the strength of the gel and further, positively influence their interactions with the mucin. In these conditions, an increased nasal residence time should be obtained, and so in better API bioavailability in the olfactory mucosa. It can be noted that the granulometric properties of the liposomes were kept unchanged at the end of these experiments (data not shown).

\subsection{API In Vitro Release}

Drug release from liposomes, hydrogels and composite formulation was performed in nasal simulated fluid, on Franz cells (Figure 6).

A sustained API release was observed with liposomes or hydrogel, and a maximal delayed release was obtained with the composite formulation (the time to reach a $50 \%$ release of API, $\mathrm{T}_{50} \%=60 \mathrm{~min}$ ) in comparison with a drug solution $\left(\mathrm{T}_{50} \%=20 \mathrm{~min}\right)$. Thus, it appears that, by modulating the nature of galenic form, and/or by using liposomes, the API diffuses according to different release kinetics. 


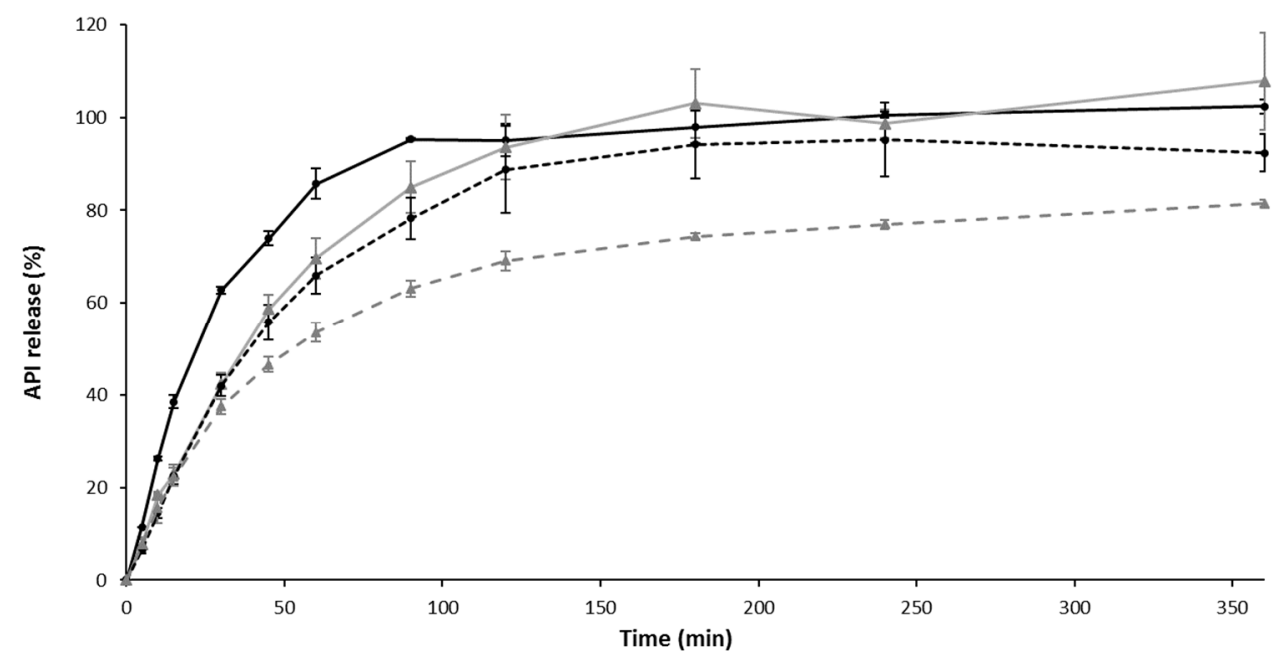

Figure 6. Active pharmaceutical ingredient (API) release in simulated nasal fluid. Each point represents mean \pm standard deviation $(\mathrm{n}=3) . \rightarrow$ Solution API $1 \mathrm{mg} / \mathrm{mL}, \longrightarrow$ API-loaded liposomes , $\rightarrow-\cdots$ Gel with API $1 \mathrm{mg} / \mathrm{mL},-\star-$ API-loaded Liposomes in gel.

Already, in the literature, it was showed that liposome incorporation into a hydrogel promoted prolonged API release, resulting in increased API residence time at the site of administration. For example, calcein release from liposomal gels was found slower in comparison to control gels, and could be further retarded by using rigid-membrane liposomes, i.e., cholesterol-based liposomes as in our formulation [70]. It is known that drug release from liposomes mainly depends on lipid composition, the size of liposomes, and the extent of lipid packing [71].

To date, the ideal pharmacokinetics profile to reach is not defined for our studied API. Considering all our results, it will be possible to optimize it by using either the drug solution, the API hydrogel, the liposomal or the API composite formulation after nasal administration.

The study of Al Asmari et al. showed that a more rapid and a greater transport of liposomal donepezil into the brain could be obtained, with similar release kinetic [12]. This probably would not be the case with our formulations. In the study of Arumugam et al., a significantly higher level of drug in the brain was found after intranasal administration of liposomes of rivastigmine compared to the intranasal administration of drug solution [14]. Moreover, these authors demonstrated the longer half-life in the brain after intranasal administration of liposomes than intranasal or oral administration of rivastigmine solution. In these conditions, the efficacy of the API into the CNS can be optimized. The best formulation to use will be defined from further in vivo pharmacokinetics and pharmacodynamics studies.

\section{Conclusions}

We based our present study on an API, acting as a promising selective BuChE inhibitor. An innovative composite formulation was designed to enable administration of this API by intranasal route, thus allowing prolonged residence time in the nasal cavity, and a controlled drug release. Such a formulation strategy should permit not only to circumvent the low API BBB-permeability, but also to decrease its systemic exposure and its potential correlated cardiac toxicity effects, and also ultimately, to increase its bioavailability in the CNS.

This formulation consists in a thermosensitive gel, endowed with mucoadhesive properties and carrying liposomes of a promising API for the treatment of AD. The entire formulation is indicated and compatible for intranasal administration, a particularly advantageous route for the outpatient management of patients suffering from this major neurodegenerative disease and having no curative treatment to date. This composite formulation can be used as a whole, or each element (solution, thermosensitive gel, liposomes) can be taken separately, enabling a defined but different API 
release profile. Further in vivo experiments will contribute to determine ideal in vivo pharmacokinetics and pharmacodynamics of this API. The formulations that we developed will thus permit to optimize API delivery into the CNS in order to obtain a therapeutic effect in AD.

Author Contributions: Conceptualization, C.R., P.D., and A.M.F.; methodology, A.-C.G., A.M.F.; formal analysis, T.A.; investigation, T.A., A.-C.G., C.P., A.D., S.C., M.S., F.B. and L.L.P.; writing-original draft preparation, T.A., A.-C.G.; writing-review and editing, A.-C.G., A.M.-F.; visualization, A.-C.G.; supervision, A.M.-F. All authors have read and agreed to the published version of the manuscript.

Funding: This research received no external funding.

Acknowledgments: This work was supported by the University of Caen (Normandie Univ, UNICAEN).

Conflicts of Interest: The authors declare no conflict of interest.

\section{References}

1. Alzheimer's Association 2016 Alzheimer's disease facts and figures. Alzheimers Dement. 2016, 12, 459-509. [CrossRef]

2. McGleenon, B.M.; Dynan, K.B.; Passmore, A.P. Acetylcholinesterase inhibitors in Alzheimer's disease. Br. J. Clin. Pharm. 1999, 48, 471-480. [CrossRef]

3. Darvesh, S.; Hopkins, D.A.; Geula, C. Neurobiology of butyrylcholinesterase. Nat. Rev. Neurosci. 2003, 4, 131-138. [CrossRef]

4. Hoffmann, M.; Stiller, C.; Endres, E.; Scheiner, M.; Gunesch, S.; Sotriffer, C.; Maurice, T.; Decker, M. Highly Selective Butyrylcholinesterase Inhibitors with Tunable Duration of Action by Chemical Modification of Transferable Carbamate Units Exhibit Pronounced Neuroprotective Effect in an Alzheimer's Disease Mouse Model. J. Med. Chem. 2019, 62, 9116-9140. [CrossRef]

5. Jakki, S.L.; Senthil, V.; Yasam, V.R.; Chandrasekar, M.J.N.; Vijayaraghavan, C. The Blood Brain Barrier and its Role in Alzheimer's Therapy: An Overview. Curr. Drug Targets 2018, 19, 155-169. [CrossRef]

6. Alexander, A.; Agrawal, M.; Uddin, A.; Siddique, S.; Shehata, A.M.; Shaker, M.A.; Ata Ur Rahman, S.; Abdul, M.I.M.; Shaker, M.A. Recent expansions of novel strategies towards the drug targeting into the brain. Int. J. Nanomed. 2019, 14, 5895-5909. [CrossRef]

7. Crowe, T.P.; Greenlee, M.H.W.; Kanthasamy, A.G.; Hsu, W.H. Mechanism of intranasal drug delivery directly to the brain. Life Sci. 2018, 195, 44-52. [CrossRef]

8. Hallschmid, M.; Benedict, C.; Schultes, B.; Perras, B.; Fehm, H.-L.; Kern, W.; Born, J. Towards the therapeutic use of intranasal neuropeptide administration in metabolic and cognitive disorders. Regul. Pept. 2008, 149, 79-83. [CrossRef]

9. Martins, P.P.; Smyth, H.D.C.; Cui, Z. Strategies to facilitate or block nose-to-brain drug delivery. Int. J. Pharm. 2019, 570, 118635. [CrossRef]

10. Misra, A.; Jogani, V.; Jinturkar, K.; Vyas, T. Recent patents review on intranasal administration for CNS drug delivery. Recent Pat. Drug Deliv. 2008, 2, 25-40. [CrossRef]

11. Fonseca-Santos, B.; Gremião, M.P.D.; Chorilli, M. Nanotechnology-based drug delivery systems for the treatment of Alzheimer's disease. Int. J. Nanomedicine 2015, 10, 4981-5003. [CrossRef]

12. Al Asmari, A.K.; Ullah, Z.; Tariq, M.; Fatani, A. Preparation, characterization, and in vivo evaluation of intranasally administered liposomal formulation of donepezil. Drug Des. Devel. 2016, 10, 205-215.

13. Yang, Z.-Z.; Zhang, Y.-Q.; Wang, Z.-Z.; Wu, K.; Lou, J.-N.; Qi, X.-R. Enhanced brain distribution and pharmacodynamics of rivastigmine by liposomes following intranasal administration. Int. J. Pharm. 2013, 452, 344-354. [CrossRef]

14. Arumugam, K.; Subramanian, G.S.; Mallayasamy, S.R.; Averineni, R.K.; Reddy, M.S.; Udupa, N. A study of rivastigmine liposomes for delivery into the brain through intranasal route. Acta Pharm. 2008, 58, 287-297. [CrossRef]

15. Ismail, M.F.; Elmeshad, A.N.; Salem, N.A.-H. Potential therapeutic effect of nanobased formulation of rivastigmine on rat model of Alzheimer's disease. Int. J. Nanomed. 2013, 8, 393-406. [CrossRef]

16. Amidon, G.L.; Lennernäs, H.; Shah, V.P.; Crison, J.R. A theoretical basis for a biopharmaceutic drug classification: The correlation of in vitro drug product dissolution and in vivo bioavailability. Pharm. Res. 1995, 12, 413-420. [CrossRef] 
17. Agrawal, M.; Saraf, S.; Saraf, S.; Antimisiaris, S.G.; Chougule, M.B.; Shoyele, S.A.; Alexander, A. Nose-to-brain drug delivery: An update on clinical challenges and progress towards approval of anti-Alzheimer drugs. J. Control. Release 2018, 281, 139-177. [CrossRef]

18. Bulbake, U.; Doppalapudi, S.; Kommineni, N.; Khan, W. Liposomal Formulations in Clinical Use: An Updated Review. Pharmaceutics 2017, 9, 12. [CrossRef]

19. Sharma, D.; Ali, A.A.E.; Trivedi, L.R. An Updated Review on: Liposomes as drug delivery system. PharmaTutor 2018, 6, 50-62. [CrossRef]

20. Peppas, N.A.; Bures, P.; Leobandung, W.; Ichikawa, H. Hydrogels in pharmaceutical formulations. Eur. J. Pharm. Biopharm. 2000, 50, 27-46. [CrossRef]

21. Giuliano, E.; Paolino, D.; Fresta, M.; Cosco, D. Mucosal Applications of Poloxamer 407-Based Hydrogels: An Overview. Pharmaceutics 2018, 10, 159. [CrossRef]

22. Soliman, G.M.; Fetih, G.; Abbas, A.M. Thermosensitive bioadhesive gels for the vaginal delivery of sildenafil citrate: In vitro characterization and clinical evaluation in women using clomiphene citrate for induction of ovulation. Drug Dev. Ind Pharm 2017, 43, 399-408. [CrossRef]

23. Wang, Y.; Jiang, S.; Wang, H.; Bie, H. A mucoadhesive, thermoreversible in situ nasal gel of geniposide for neurodegenerative diseases. PLoS ONE 2017, 12, e0189478. [CrossRef]

24. Aderibigbe, B.A. In Situ-Based Gels for Nose to Brain Delivery for the Treatment of Neurological Diseases. Pharmaceutics 2018, 10, 40. [CrossRef]

25. Mura, P.; Mennini, N.; Nativi, C.; Richichi, B. In situ mucoadhesive-thermosensitive liposomal gel as a novel vehicle for nasal extended delivery of opiorphin. Eur. J. Pharm. Biopharm. 2018, 122, 54-61. [CrossRef]

26. Jain, D.S.; Bajaj, A.N.; Athawale, R.B.; Shikhande, S.S.; Pandey, A.; Goel, P.N.; Gude, R.P.; Patil, S.; Raut, P. Thermosensitive PLA based nanodispersion for targeting brain tumor via intranasal route. Mater. Sci. Eng. C. Mater. Biol. Appl. 2016, 63, 411-421. [CrossRef]

27. Bitter, C.; Suter-Zimmermann, K.; Surber, C. Nasal drug delivery in humans. Curr. Probl. Derm. 2011, 40, 20-35.

28. Nasal preparations. In European Pharmacopoeia; ed. 9.5; EDQM Council of Europe: Strasbourg, France, 2008; pp. 940-942.

29. Ellman, G.L.; Courtney, K.D.; Andres, V.; Feather-Stone, R.M. A new and rapid colorimetric determination of acetylcholinesterase activity. Biochem. Pharm. 1961, 7, 88-95. [CrossRef]

30. Rochais, C.; Lecoutey, C.; Gaven, F.; Giannoni, P.; Hamidouche, K.; Hedou, D.; Dubost, E.; Genest, D.; Yahiaoui, S.; Freret, T.; et al. Novel multitarget-directed ligands (MTDLs) with acetylcholinesterase (AChE) inhibitory and serotonergic subtype 4 receptor (5-HT4R) agonist activities as potential agents against Alzheimer's disease: The design of donecopride. J. Med. Chem. 2015, 58, 3172-3187. [CrossRef]

31. Jourdan, J.-P.; Since, M.; El Kihel, L.; Lecoutey, C.; Corvaisier, S.; Legay, R.; Sopkova-de Oliveira Santos, J.; Cresteil, T.; Malzert-Fréon, A.; Rochais, C.; et al. Novel benzylidenephenylpyrrolizinones with pleiotropic activities potentially useful in Alzheimer's disease treatment. Eur. J. Med. Chem. 2016, 114, 365-379. [CrossRef]

32. Bangham, A.D.; Standish, M.M.; Watkins, J.C. Diffusion of univalent ions across the lamellae of swollen phospholipids. J. Mol. Biol. 1965, 13, 238-252. [CrossRef]

33. Schmolka, I.R. Artificial skin. I. Preparation and properties of pluronic F-127 gels for treatment of burns. J. Biomed. Mater. Res. 1972, 6, 571-582. [CrossRef] [PubMed]

34. Greig, N.H.; Lahiri, D.K.; Sambamurti, K. Butyrylcholinesterase: An important new target in Alzheimer's disease therapy. Int. Psychogeriatr. 2002, 14, 77-91. [CrossRef] [PubMed]

35. Giacobini, E. Cholinesterase inhibitors: New roles and therapeutic alternatives. Pharm. Res. 2004, 50, 433-440. [CrossRef]

36. Furukawa-Hibi, Y.; Alkam, T.; Nitta, A.; Matsuyama, A.; Mizoguchi, H.; Suzuki, K.; Moussaoui, S.; Yu, Q.-S.; Greig, N.H.; Nagai, T.; et al. Butyrylcholinesterase inhibitors ameliorate cognitive dysfunction induced by amyloid- $\beta$ peptide in mice. Behav. Brain Res. 2011, 225, 222-229. [CrossRef]

37. Elumalai, K.; Ali, M.A.; Elumalai, M.; Eluri, K.; Srinivasan, S. Acetylcholinesterase enzyme inhibitor activity of some novel pyrazinamide condensed 1,2,3,4-tetrahydropyrimidines. Biotechnol. Rep. 2015, 5, 1-6. [CrossRef]

38. Dafferner, A.J.; Lushchekina, S.; Masson, P.; Xiao, G.; Schopfer, L.M.; Lockridge, O. Characterization of butyrylcholinesterase in bovine serum. Chem. -Biol. Interact. 2017, 266, 17-27. [CrossRef] 
39. Wu, J.; Tian, Y.; Wang, S.; Pistolozzi, M.; Jin, Y.; Zhou, T.; Roy, G.; Xu, L.; Tan, W. Design, synthesis and biological evaluation of bambuterol analogues as novel inhibitors of butyrylcholinesterase. Eur. J. Med. Chem. 2017, 126, 61-71. [CrossRef]

40. Dighe, S.N.; Deora, G.S.; De la Mora, E.; Nachon, F.; Chan, S.; Parat, M.-O.; Brazzolotto, X.; Ross, B.P. Discovery and Structure-Activity Relationships of a Highly Selective Butyrylcholinesterase Inhibitor by Structure-Based Virtual Screening. J. Med. Chem. 2016, 59, 7683-7689. [CrossRef]

41. Sun, H.; Nguyen, K.; Kerns, E.; Yan, Z.; Yu, K.R.; Shah, P.; Jadhav, A.; Xu, X. Highly predictive and interpretable models for PAMPA permeability. Bioorg. Med. Chem. 2017, 25, 1266-1276. [CrossRef]

42. Masuda, Y. Cardiac effect of cholinesterase inhibitors used in Alzheimer's disease-from basic research to bedside. Curr. Alzheimer Res. 2004, 1, 315-321. [CrossRef] [PubMed]

43. Quraishi, M.S.; Jones, N.S.; Mason, J. The rheology of nasal mucus: A review. Clin. Otolaryngol. Allied Sci. 1998, 23, 403-413. [CrossRef] [PubMed]

44. Ruel-Gariépy, E.; Leclair, G.; Hildgen, P.; Gupta, A.; Leroux, J.-C. Thermosensitive chitosan-based hydrogel containing liposomes for the delivery of hydrophilic molecules. J. Control. Release 2002, 82, 373-383. [CrossRef]

45. Mayer, L.D.; Tai, L.C.; Ko, D.S.; Masin, D.; Ginsberg, R.S.; Cullis, P.R.; Bally, M.B. Influence of vesicle size, lipid composition, and drug-to-lipid ratio on the biological activity of liposomal doxorubicin in mice. Cancer Res. 1989, 49, 5922-5930.

46. Ahmad, E.; Feng, Y.; Qi, J.; Fan, W.; Ma, Y.; He, H.; Xia, F.; Dong, X.; Zhao, W.; Lu, Y.; et al. Evidence of nose-to-brain delivery of nanoemulsions: Cargoes but not vehicles. Nanoscale 2017, 9, 1174-1183. [CrossRef]

47. Oberdörster, G.; Oberdörster, E.; Oberdörster, J. Nanotoxicology: An Emerging Discipline Evolving from Studies of Ultrafine Particles. Environ. Health Perspect. 2005, 113, 823-839. [CrossRef]

48. Morrison, E.E.; Costanzo, R.M. Morphology of the human olfactory epithelium. J. Comp. Neurol. 1990, 297, 1-13. [CrossRef]

49. Yasir, M.; Sara, U.V.S.; Chauhan, I.; Gaur, P.K.; Singh, A.P.; Puri, D. Ameeduzzafar Solid lipid nanoparticles for nose to brain delivery of donepezil: Formulation, optimization by Box-Behnken design, in vitro and in vivo evaluation. Artif. CellsNanomed. Biotechnol. 2018, 46, 1838-1851.

50. Bonaccorso, A.; Musumeci, T.; Serapide, M.F.; Pellitteri, R.; Uchegbu, I.F.; Puglisi, G. Nose to brain delivery in rats: Effect of surface charge of rhodamine B labeled nanocarriers on brain subregion localization. Colloids Surf. B Biointerfaces 2017, 154, 297-306. [CrossRef]

51. Gänger, S.; Schindowski, K. Tailoring Formulations for Intranasal Nose-to-Brain Delivery: A Review on Architecture, Physico-Chemical Characteristics and Mucociliary Clearance of the Nasal Olfactory Mucosa. Pharmaceutics 2018, 10, 116. [CrossRef]

52. Groo, A.-C.; Mircheva, K.; Bejaud, J.; Ailhas, C.; Panaiotov, I.; Saulnier, P.; Ivanova, T.; Lagarce, F. Development of 2D and 3D mucus models and their interactions with mucus-penetrating paclitaxel-loaded lipid nanocapsules. Pharm. Res. 2014, 31, 1753-1765. [CrossRef] [PubMed]

53. Groo, A.-C.; Lagarce, F. Mucus models to evaluate nanomedicines for diffusion. Drug Discov. Today 2014, 19, 1097-1108. [CrossRef] [PubMed]

54. Schlegel, P.N.; Histrelin Study Group. Efficacy and safety of histrelin subdermal implant in patients with advanced prostate cancer. J. Urol. 2006, 175, 1353-1358. [CrossRef]

55. Thorn, R.M.S.; Greenman, J.; Austin, A. An in vitro study of antimicrobial activity and efficacy of iodine-generating hydrogel dressings. J. Wound Care 2006, 15, 305-310. [CrossRef] [PubMed]

56. Zhang, Z.-Q.; Kim, Y.-M.; Song, S.-C. Injectable and quadruple-functional hydrogel as an alternative to intravenous delivery for enhanced tumor targeting. Acs Appl. Mater. Interfaces 2019, 11, 34634-34644. [CrossRef] [PubMed]

57. Liu, Y.; Yang, F.; Feng, L.; Yang, L.; Chen, L.; Wei, G.; Lu, W. In vivo retention of poloxamer-based in situ hydrogels for vaginal application in mouse and rat models. Acta Pharm. Sin. B 2017, 7, 502-509. [CrossRef]

58. Russo, E.; Villa, C. Poloxamer Hydrogels for Biomedical Applications. Pharmaceutics 2019, 11, 671. [CrossRef]

59. Singh-Joy, S.D.; McLain, V.C. Safety assessment of poloxamers 101, 105, 108, 122, 123, 124, 181, 182, 183, 184, $185,188,212,215,217,231,234,235,237,238,282,284,288,331,333,334,335,338,401,402$, 403, and 407, poloxamer 105 benzoate, and poloxamer 182 dibenzoate as used in cosmetics. Int. J. Toxicol. 2008, 27, $93-128$.

60. Van Tomme, S.R.; Storm, G.; Hennink, W.E. In situ gelling hydrogels for pharmaceutical and biomedical applications. Int. J. Pharm. 2008, 355, 1-18. [CrossRef] 
61. Pereira, G.G.; Dimer, F.A.; Guterres, S.S.; Kechinski, C.P.; Granada, J.E.; Cardozo, N.S.M. Formulation and characterization of poloxamer $407^{\circledR}$ : Thermoreversible gel containing polymeric microparticles and hyaluronic acid. Química Nova 2013, 36, 1121-1125. [CrossRef]

62. Dumortier, G.; Grossiord, J.L.; Agnely, F.; Chaumeil, J.C. A review of poloxamer 407 pharmaceutical and pharmacological characteristics. Pharm. Res. 2006, 23, 2709-2728. [CrossRef] [PubMed]

63. Bochot, A.; Fattal, E.; Gulik, A.; Couarraze, G.; Couvreur, P. Liposomes Dispersed Within a Thermosensitive Gel: A New Dosage Form for Ocular Delivery of Oligonucleotides. Pharm. Res. 1998, 15, 1364-1369. [CrossRef] [PubMed]

64. Wu, G.; Lee, K.Y.C. Interaction of Poloxamers with Liposomes: An Isothermal Titration Calorimetry Study. J. Phys. Chem. B 2009, 113, 15522-15531. [CrossRef] [PubMed]

65. Cho, E.C.; Lim, H.J.; Shim, J.; Park, J.Y.; Dan, N.; Kim, J.; Chang, I.-S. Effect of polymer characteristics on structure of polymer-liposome complexes. J. Colloid Interface Sci. 2007, 311, 243-252. [CrossRef] [PubMed]

66. Pembouong, G.; Morellet, N.; Kral, T.; Hof, M.; Scherman, D.; Bureau, M.-F.; Mignet, N. A comprehensive study in triblock copolymer membrane interaction. J. Control. Release 2011, 151, 57-64. [CrossRef] [PubMed]

67. Tian, J.L.; Ke, X.; Chen, Z.; Wang, C.J.; Zhang, Y.; Zhong, T.C. Melittin liposomes surface modified with poloxamer 188: In vitro characterization and in vivo evaluation. Pharmazie 2011, 66, 362-367.

68. Karavasili, C.; Fatouros, D.G. Smart materials: In situ gel-forming systems for nasal delivery. Drug Discov. Today 2016, 21, 157-166. [CrossRef]

69. Tuğcu-Demiröz, F. Development of in situ poloxamer-chitosan hydrogels for vaginal drug delivery of benzydamine hydrochloride: Textural, mucoadhesive and in vitro release properties. Marmara Pharm. J. 2017, 21, 762-770. [CrossRef]

70. Mourtas, S.; Fotopoulou, S.; Duraj, S.; Sfika, V.; Tsakiroglou, C.; Antimisiaris, S.G. Liposomal drugs dispersed in hydrogels. Effect of liposome, drug and gel properties on drug release kinetics. Colloids Surf. B Biointerfaces 2007, 55, 212-221. [CrossRef]

71. Lindner, L.H.; Hossann, M. Factors affecting drug release from liposomes. Curr. Opin. Drug Discov. Devel. 2010, 13, 111-123.

(C) 2020 by the authors. Licensee MDPI, Basel, Switzerland. This article is an open access article distributed under the terms and conditions of the Creative Commons Attribution (CC BY) license (http://creativecommons.org/licenses/by/4.0/). 